\title{
Loans may keep CERN collider on target
}

Munich. The European Laboratory for Parland, may have to take out bank loans to keep on target the construction of its accelcrator, the Large Hadron Collider (LHC).

Such a move would reverse a policy agreed only two years ago that all construction work should be paid for out of the annual subscriptions of CERN's 19 member unexpected decision in July to reduce significantly its contributions for the next few

The severity of Germany's proposed reductions -8.5 per cent of its previously agreed contribution for 1997 and 1998, and 9.3 per cent for the following two years will have a major impact on the construction of the SFr2.6-billion (US\$2.08-billion) LHC, the world's largest basic research project.

CERN's committee of council, which met in Geneva last week, acknowledged that raising loans, to be paid back over a longer period of years, may be the only way to meet the goal of completing the LHC by the year 2005. The committee, which is made up of representatives of member states, rejected requests from Germany to be considered a special case.

The committee said that if Germany reduces its subscription, then all other member states will follow suit. Indeed, many countries would view the chance to save money on international projects with some relief. France, for example, has already announced plans to reduce its subscription to the laboratory next year by 2 per cent (see Nature 383, 289; 1996).

Contributions are decided by a formula based primarily on the size of a country's gross national product. Such reductions could undermine CERN's attempts to raise funding for the LHC from other countries, ticle Physics (CERN) in Geneva, Switzerstates. It is a direct result of Germany's years (see Nature 382, 285; 1996).

in particular Japan and the United States, to bring forward the final completion date for the collider.

The proposed funding for the LHC had already been severely stretched before member states finally approved the project in 1994. A decision was made then to build the LHC in two phases (see Nature 372, 713; 1994) in order to spread construction costs over a longer period, although CERN scientists have always viewed this as a compromise that will not provide optimum scientific return.

It had been hoped that the original timetable, involving full operation in 2005 , could be restored by contributions from non-member states. By last July this hope appeared justified. The United States, Japan, Russia and Canada were talking seriously about contributions that could add up to a total of SFr450 million.

But if all member states reduce their contributions in line with Germany, then these additional contributions could fail to materialize, says Maurice Jacob, who manages CERN's relations with its member states. Negotiations have been carried out on the assumption that the 2005 target date would be achieved, he says, but with such a large drop in CERN's own budget this now seems in doubt.

Member states are acutely aware of what is at stake. One member of the CERN committee said that it was "ironic" that, in its attempts to meet the criteria for joining a single European currency, "Germany is threatening the largest European cooperative project in science".

The committee expressed little sympathy for Germany's situation. In a statement issued after the meeting, Christopher Llewellyn Smith, CERN's director general, pointed out that many countries face

\section{US review to examine university research}

Washington. President Bill Clinton last week ordered a comprehensive review of the way federal government policies affect scientific research in US universities. The review will be carried out by the President's Council of Advisers on Science and Technology (PCAST), which has been told to report by the end of next June.

The PCAST Committee on Fundamental Science - chaired jointly by Harold Varmus, director of the National Institutes of Health, and Neil Lane, director of the National Science Foundation, together with Ernest Moniz, of the White House's Office of Science and Technology Policy - will set up an interagency task force to conduct the review.

According to the White House, this will focus on "what stresses [research] universities may be faced with and whether the federal government might be contributing to them".

Judith Rodin, president of the University of Pennsylvania and a member of PCAST, says that the review will study inconsistencies in policies between government agencies which make compliance "weighty and confusing and difficult" for research institutions.

According to Lane, the review is needed to dispel various myths. "There is not a clear dialogue going on between government and higher education," he says. Priorities will include federal support for undergraduate, graduate and postdoctoral science education; the impact of Washington's policies on government-university research partnerships; and streamlining regulations without damaging researcher accountability. Meredith Wadman

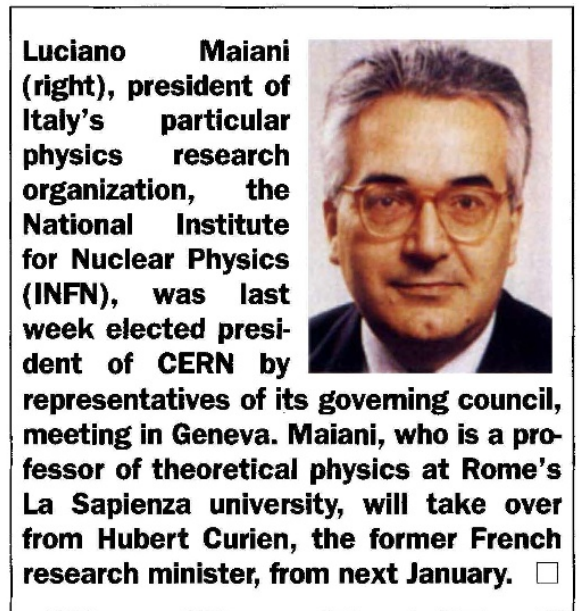

similar economic difficulties.

Germany's argument that the cost of reunification makes its position worse than that of other member states has made little impact, as Germany has already been given a special dispensation to compensate for this. A three-year agreement allowing Germany to reduce its contributions from 25 per cent of the total CERN budget - the ceiling for any contribution from a single member - to 22.5 per cent has been extended by two years and now ends in 1998 . Nonetheless Germany remains the highest contributor to CERN.

Officials at the laboratory are preparing options that will be put to the committee in an extraordinary meeting on 7 November, before a meeting of the full council in December.

During this period, efforts will be made to persuade Germany to modify its position, although a spokesman for the German research ministry says that a change of heart is unlikely. But officials will develop a range of financial options that could be introduced to help keep the project on track if a compromise proves impossible.

Some help has come from the fact that inflation has been lower than expected in Switzerland, allowing CERN to save SFr60 million over the past two years. Llewellyn Smith has said that this can be used to help bridge the shortfall, despite the risk that CERN would be unable to cushion any future inflation that was higher than expected.

But the committee of council accepted that the only way to meet the remaining shortfall would be to take out loans and pay for the machine over a longer period. CERN did this previously to pay for its Large Electron-Proton (LEP) collider. But in 1994 CERN's council voted against loans, because of opposition from the finance ministers of many member states to the possible extra costs involved. This decision now seems likely to be reversed.

Alison Abbott 